\title{
Images in Anesthesia: Anesthetic implications of persistent left superior vena cava
}

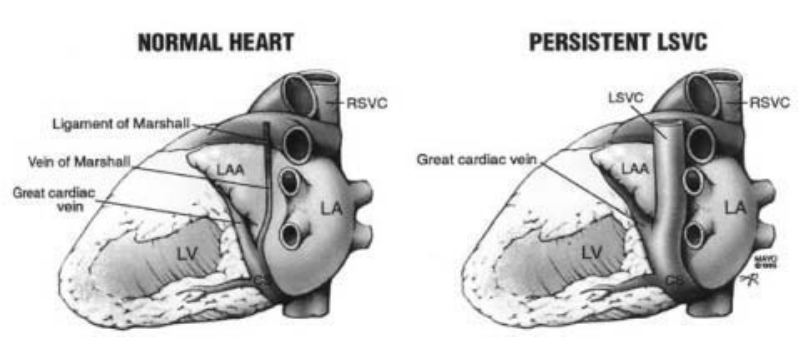

FIGURE 1 Schematic diagrams showing the ligament/vein of Marshall in normal hearts (left) and persistent left superior vena cava (LSVC; right). CS = coronary sinus; LA = left atrium; LAA = left atrial appendage; $\mathrm{LV}=$ left ventricle; $\mathrm{RA}=$ right atrium; RSVC = right superior vena cava. Reprinted with permission from Hurst's the Heart. Copyright 2001, McGraw-Hill Medical Publishing Division.

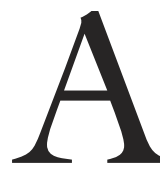
persistent left superior vena cava (PLSVC) has an incidence of $0.3 \%$ of the population. ${ }^{1}$ During normal embryologic development, the left brachiocephalic vein develops as a bridge between the left and right anterior cardinal veins. The caudal part of the right anterior cardinal vein becomes the normal superior vena cava (SVC) and the left anterior cardinal vein caudal to the left brachiocephalic vein normally collapses and degenerates. If this portion of the left anterior cardinal remains patent, it becomes a PLSVC which opens into the right atrium via the vein of Marshall and dilated coronary sinus (Figure 1). This can result in a bilateral SVC or the absence of a right SVC. ${ }^{2}$

Typically, PLSVCs are found by chest radiograph after left subclavian or jugular venous catheter insertion, especially with a pulmonary artery catheter (PAC). The catheter is seen along the left side of the mediastinum (Figure 2). Placement of a central venous catheter or PAC into a PLSVC might be mistaken for placement into other areas that overlie a PLSVC on a radiograph such as the subclavian or carotid artery, mediastinum, pleural space, or thoracic duct. Lastly, the use of retrograde cardioplegia in the coronary sinus during asystolic heart surgery may be ineffective. ${ }^{3}$

James J. Konvicka MD

Frank J. Villamaria MD

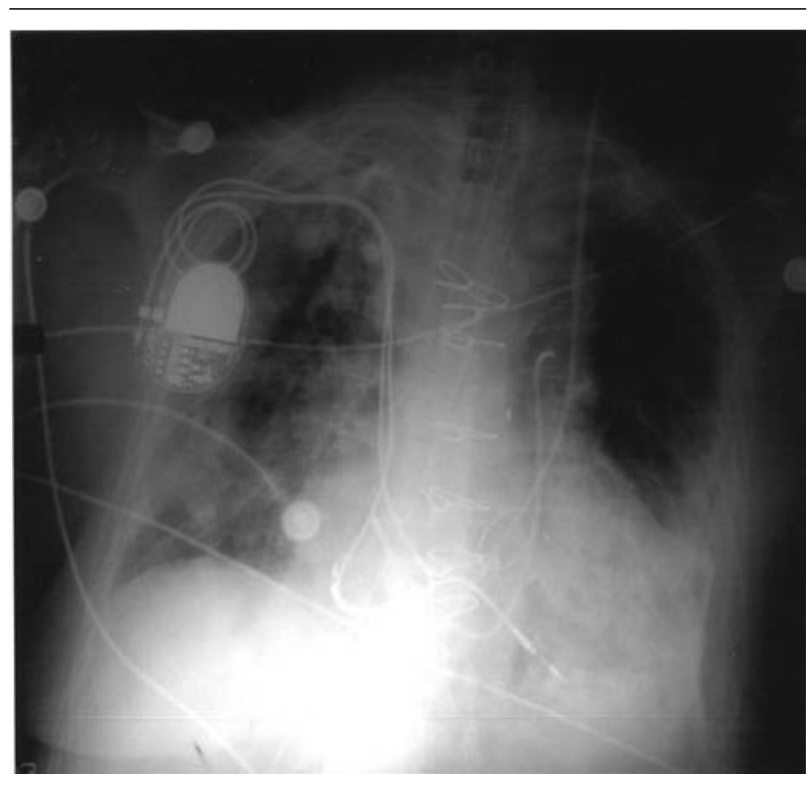

FIGURE 2 Chest radiograph (antero-posterior view) showing the typical appearance of a pulmonary artery catheter passing through a persistent left superior vena cava in a patient with a double superior vena cava connected by a left brachiocephalic vein. Chest radiograph of a female patient taken 10/01/2001 at Scott \& White Memorial Hospital, Temple, Texas.

Scott \& White Memorial Hospital and Clinic Scott, Sherwood and Brindley Foundation The Texas A\&M University System

Health Science Center College of Medicine, Temple, USA

E-mail: jkonvicka@swmail.sw.org

\section{References}

1 Geissler W, Albert M. Persistierende linke obere Hohlvene und Mitralstenose. A Gesamte Inn Med 1956; 11: 865.

2 Tak T, Crouch E, Drake GB. Persistent left superior vena cava: incidence, significance and clinical correlates (Letter). Int J Cardiol 2002; 82: 91-3.

3 Sarodia BD, Stoller JK. Persistent left superior vena cava: case report and literature review. Respir Care 2000; 45: 411-6. 